\title{
Under reporting of child sexual abuse- The barriers guarding the silence
}

\author{
Suhas Chandran ${ }^{1, *}$, Smriti Bhargava ${ }^{2}$, Kishor $\mathbf{M}^{3}$ \\ ${ }^{1}$ Senior Resident, ${ }^{2} \mathrm{MBBS},{ }^{3}$ Associate Professor, Dept. of Psychiatry, ${ }^{1}$ St. John's Medical College \& Hospital, St. John's National Academy \\ of Health Sciences, Bangalore, Karnataka, ${ }^{2,3}$ JSS Medical College and Hospital, JSS Academy of Higher Education \& Research, Mysore,
} Karnataka, India

*Corresponding Author: Smriti Bhargava

Email: 2112.smriti@gmail.com

\begin{abstract}
Under-reporting of Child Sexual Abuse (CSA) is rampant in India, despite which India has the highest number of CSA cases in the world, the ramifications of which are enormous. Other than the obvious reasons of stigma and fear of the perpetrator, multiple other factors come into play, such as attitudes and responses of guardians, which themselves prevent children from reporting and may even lead to retraction of the disclosure. The Indian cultural etiquette strongly advocates obedience towards older individuals, which may result in the child acquiescing to the perpetrator's demands. The fear of legal entanglements discourages guardians from seeking legal assistance. In spite of the Protection of Children from Sexual Offences Act of 2012 emphasizing the role of medical professionals in mandatory reporting of CSA, there is no further social support made available by the Government for use by victims post-reporting. The stigmatization, powerlessness, traumatic sexualization and betrayal experienced by the child lead to significant negative consequences which are often long lasting and alarming. This article touches upon the obvious as well as inconspicuous causes of under-reporting, challenges faced and long term implications for the victims. Also, suggestions to minimize the incidence of CSA and its attendant consequences are discussed, like conceptualization of a multiagency, multi-tier team approach consisting of medical, legal and supportive aspects, addressing the root causes of childhood maltreatment like poverty and environmental safety, besides raising public awareness by sensitizing general public and training children to identify CSA through creative and culturally popular methods.
\end{abstract}

Keywords: Child sexual abuse, Underreporting, POCSO Act, Childhood maltreatment.

Child sexual abuse (CSA) remains an underreported crime throughout the world, despite extensive research and resources committed both to improving investigative techniques and helping children disclose their experiences. One of the most comprehensive definitions is given by the Standing Committee on Sexually Abused Children (SCOSAC, 1984) stating "Any child below the age of consent may be deemed to have been sexually abused when a sexually matured person has engaged or permitted the engagement of that child in any activity of a sexual nature which is intended to lead to sexual gratification of the sexually mature person". ${ }^{1}$

The issue of CSA is still a taboo in India and majority of the people remain silent about the issue. This silence is due to the fear of indignity, denial from the community, social stigma, distrust for the governmental organisations, and a communication gap between parents and children. ${ }^{2}$ As per the 2001 census, children constitute $42 \%$ of the country's total population. A total of 33,098 cases of sexual abuse in children were reported in the nation during the year 2011 while 7,112 cases of child rape were reported in the same year. ${ }^{2,3}$

Even with under reporting, India has the world's largest number of CSA cases, so one can only imagine what the real numbers could be. Every 155th minute a child, less than 16 years and for every 13th hour child under 10 is raped. One in every 10 children is sexually abused at any point of time. ${ }^{4}$ Studies propose that over 7,200 children, including infants, are raped every year and it is believed that several cases go unreported. It is estimated by the government that $40 \%$ of India's children are susceptible to threats like being homeless, trafficking, drug abuse, forced labor, and crime. ${ }^{5}$ In India, every second child is being exposed to one or the other form of sexual abuse and every fifth child faces critical forms of it. ${ }^{3}$

One way of surveying the problem is to use the analogy of an iceberg, with the relatively small number of disclosed occurrences being those that are "above the surface" and the much larger majority of occurrences that not disclosed to authorities as being "below the surface". ${ }^{6}$ This syntax is more useful than traditional "incidence" or "prevalence" terms, since the occurrence reported in studies varies widely depending upon which criteria and which group is being studied and shows that to a large extent abuse has been a hidden phenomenon with very few number of abused children reaching the notice of the authorities. CSA is certainly not a rare phenomenon but still large numbers of cases go unreported and as a result many children continue to suffer the high degree of physical, emotional and psychosocial consequences in silence.

A number of reasons have been observed for not disclosing the abuse, stemming from the complex interplay of individual, familial and social factors. ${ }^{7}$ Firstly, children do not disclose abuse because they are blackmailed or threatened into silence and are afraid of punishment. ${ }^{8}$ In addition, some children might not even be able to understand what abuse fundamentally is. Secondly, even if the child does talk about it explicitly, the age old belief that children lie prevents adults from taking the right action. Another facet to this is that it might be too disturbing to comprehend, and believing that it couldn't have happened is easier than facing the truth that their child went through such an excruciating ordeal. When adults do not respond adequately, it makes the child less receptive to the severity of the issue and he/she might not bring it up again, believing that it may not be anything to be 
overly worried about. This, mixed with the stigmatizing nature of sexual abuse further adds to underreporting of CSA. A chief concern in India similar to other south Asian countries is the dearth of efficient monitoring of various juvenile residential institutes and the lack of punishment for institutes that do not follow the laws.

In fact, children who report sexual abuse may start to retract their original statement because of pressure from disbelieving adults, which results in fear and anxiety in the child. Hence, retraction of the child's statement is not only because of the child's fear of the perpetrator (which undoubtedly is also true in many instances); it is the so-called caregivers and protectors of the child, who are responsible for the child's failure to disclose abuse and for his/her retraction of the abuse statement later on, because of their intrinsic lack of belief in the child's experience and account.

Children in Indian societies grow up in an atmosphere where they are expected to respect their elders and obey them. Disobedience is regarded as sign of bad upbringing and is treated as a disgrace. A rigid obedience may compel the child to not disclose the activities of sexual offenders/resist them. ${ }^{9}$ Looking at the open family systems in our country, most children fall prey to being abused by someone known to them rather than a stranger. According to data collected by the National Crime Records Bureau, a survey sponsored by Women and Child Development ministry in association with UNICEF found that in 94.8 percent of cases, children were raped by someone known to them. ${ }^{10}$ This familiarity of the family with the perpetrator often stops the parents from taking stringent action.

Another significant issue is the presence of factors that confound the identification of CSA like many instances of CSA don't include penetrant sex, victims usually clean themselves following attack, and hence the medical investigation does not provide any evidence of rape. ${ }^{5}$ CSA victims and their families experience a panorama of legal proceedings that can extend for several years. Adding to the problem, is the fact that the execution of laws and initiatives in India is a challenge which is further precipitated by lack of funding for programs for child safety. ${ }^{11}$

The protection of children from sexual offenses act (POCSO Act ) of 2012 re-emphasised the role of a doctor in providing care for patients of CSA within the legal framework. It is now mandatory for doctors to register a medico-legal case in all cases of child sexual abuse. Failure of reporting could result in six months imprisonment and/or a fine under Sec 21 of the Act. ${ }^{12}$ Nonetheless, the mandatory reporting clause in the law simply does not work without a robust child protection system in place, which our country lacks. In a survey, $62.5 \%$ of child sexual abuse survivors claimed they were uncomfortable with the mandatory reporting clause. Many attributed this to the lack of social support after the reporting. Others were convinced that the police and other criminal institutions were not equipped to understand the nuances of child sexual abuse. ${ }^{13}$

A framework inclusive of four distressing dynamics can facilitate an efficient understanding of the effects of child sexual abuse. These include: stigmatization, powerlessness, traumatic sexualisation and betrayal. These are identified as the core of the psychological and psychiatric injury inflicted by abuse. ${ }^{14}$ Studies clearly demonstrate that sexually abused children have more symptoms than non-abused children of the same age group. The duration and frequency of the abuse, penetration, relationship of the perpetrator to the child, force, and maternal support affected the degree of symptomatology. ${ }^{15}$ The initial effects indicate reactions of fear, anger and hostility, anxiety, aggression, and sexually inappropriate behaviour. Frequently reported long-term effects include self-destructive behaviour depression and anxiety, poor self-esteem, feelings of isolation and stigma, substance abuse, difficulty in trusting others, a tendency toward re-victimization, and sexual maladjustment. ${ }^{16}$

The consequences of CSA are alarming; hence, inflexible measures should be taken for its prevention and control. At the same time measures should also be taken to correct the under reporting of such instances. Early identification could mean early intervention and treatment, potentially mitigating some of the longer-term impact. Though the POCSO Act is an excellent piece of legislation and it recognizes almost every known form of sexual abuse against children as a punishable offence, a few challenges remain unconquered.

A multi-dimensional, multi-agency team and multi-tier approach including access to psychosocial support can be made available to deliver holistic and comprehensive care under one roof for victims of child sexual abuse. The presence of such a system coupled with an ease of access can encourage victims to reach out. Unfortunately, no doctor, whether a general practitioner or a gynaecologist or a paediatrician are given any training regarding child abuse examination, interviewing, how to take care, rehabilitation procedures, and the medical and psychological needs of the child. ${ }^{17}$ As a result, many victims decide not to pursue their case. ${ }^{18}$ Hence, continued medical education programs for interns and senior residents should be made mandatory in every medical college in our country. This combined with intensive training workshops for undergraduates and postgraduates as a part of their curriculum akin to the Basic and Advanced Life Support training will further equip them to assess and provide necessary help to a victim of child sexual abuse.

Another strategy worth looking at is, if we can teach adults in the general population to identify the occurrence of CSA early. Nonetheless, because psychological and behavioural indicators of CSA can be non-specific as they also occur after a child experiences non-CSA stressors, abuse, and neglect, it may not be appropriate to teach adults to use indicators to identify just CSA alone. Therefore, adults in the general public could be trained by mental health professionals via CSA specific education programs so that along with the core concept of CSA they can also be taught to identify more general behaviour's indicative of stress, and to then ask these children about CSA. This allows for the opportunity of intervention and treatment of a range of abuse and neglect, recognizing the often overlapping nature of abuse. Many children also fear that their parents would beat 
them if they told their parents about the same. Parents should therefore also be taught to avoid negative reactions and support the child when they confide in them about abuse since the threat of retaliation is a major impediment against reporting abuse.

Children, in particular, need effective services to help them report abuse. These services must be safe, confidential and easy to use, and must reach out to marginalised and excluded sections, such as orphans, street children and minority ethnic groups.In concordance to this, professionals and criminal justice officials should remember that dis-ability does not confer an immunity to sexual abuse but creates an additional risk factor and that if they overlook children with disabilities they add to a perception that abuse against a disabled child or young person matters less than abuse against other more "normal" children and/or that perpetrators will not be as rigorously pursued or brought to justice. ${ }^{19}$ Throwing light on male child sexual abuse, studies show that the main barrier that was noticed was the misconception of superiority of a male victim due to gender (patriarchism) and an expectation that he will outgrow the experience. ${ }^{20}$ In a developing country like India children hailing from rural areas migrate to cities in search of jobs and better living standard and fall prey to drug peddling and sexual exploitation. ${ }^{21}$ Also, children who trade sex for food or other forms of support are unwilling to jeopardize this survival tactic by reporting the abuse against themselves.

Programs aimed at training children about identifying when they are being abused and what forms the basic fundamentals of abuse should be carried out. This can be inculcated in the school curriculum at various levels. Regular workshops for high risk groups especially with an educationally impoverished background conducted by mental health professionals like psychiatrists in conjunction with NGOs can also be done. Having well informed children will go a long way in tackling this crime. Gender awareness and sensitisation is the key to tackle discrimination associated with abuse. This should include working with boys and men to address dominant attitudes towards women, educate young boys about speaking up as well as work to strengthen the social status of women and girls by various street plays or cultural performances.

Ultimately the goal for all societies should be to completely eradicate CSA, and this will only occur with better educational programs. Chronic lack of awareness of their own rights and resources and lack of understanding as to how to report sexual abuse leads to underreporting. Hence, public awareness activities are an important part of an overall approach to addressing child abuse and neglect. Such activities have the potential to reach diverse community audiences and effectively enable coordinated efforts across different sectors of society, parents and prospective parents, children and community members, especially professionals, who are critical to the identification and reporting of abuse. The commercial sexual exploitation of children is an atrocity and is symbolic of a perversion of the natural order where adults should be there to protect and nurture children, not to take advantage of their emotionally and physically vulnerable state. The families should report violations without feeling threatened by the fear of retaliation by the abuser or the society. In order to stop child sexual exploitation, families must get involved with helping to find and punish criminals. ${ }^{22}$

Hence, the reporting of abuse is fundamental to keeping children safe. Under-reporting perpetuates a lack of accountability for the abuse, since it underplays the scale of the problem. The most effective approaches will be to address the root causes of maltreatment by addressing issues of poverty, housing, employment, schools, health-care and other community and neighbourhood systems that build financial, human and social capital.

\section{References}

1. Definition of Child Sexual Abuse. London: Standing Committee on Sexually Abused Children; 1984.

2. Study on Child Abuse: India 2007. India, Ministry of Women and Child development Government of India. 2007. [Last cited on 2014 Aug 09]. Available from: wcd.nic.in/childabuse.pdf

3. Behere P, Sathyanarayana Rao T, Mulmule A. Sexual abuse in women with special reference to children: Barriers, boundaries and beyond. Indian J Psychiatry. 2013;55(4):316.

4. S. Vidhya. Impact of sexual abuse on children and intervention strategies. Research on humanities and social sciences. ISSN 2224-5766 (Paper) ISSN 2225-0484 (Online). 2017;7(17):36

5. Breaking the silence. Child sexual abuse in India. USA, Humans rights watch. 2013. [Last cited on 2014 Aug 09]. Available from:

http://www.hrw.org/sites/default/files/reports/india0113ForUpl oad.pdf.

6. Sedlak A, Mettenburg J, Basena M, Petta I, McPherson K, Greene A, Li S. Fourth National incidence study of child abuse and neglect (NIS-4): Report to Congress. Washington, DC: U.S. Department of Health and Human Services, Administration for Children, Youth and Families; 2010

7. Malhotra S, Biswas P, Child Sexual Abuse in Clinical Practice: Identification and Management. JIACAM. 2005;1(2):66-78

8. Seshadri S, Ramaswamy S. Our failure to protect sexually abused children: Where is our 'willing suspension of disbelief'?. Indian J Psychiatry. 2017;59(2):233.

9. Pallavi Nautiyal, Arun Mal, Towards Protection of Children against Sexual Abuse: No Child's Play, 3 NUJS L. Rev. 77 2010

10. [Internet]. Ncrb.gov.in. 2016 [cited 20 July 2018]. Available from: http://ncrb.gov.in/StatPublications/CII/CII2016/pdfs/Crime\%2 0Statistics\%20-\%202016.pdf

11. India: UNICEF; 2010. [Last cited on 2014 Aug 09]. The legislative and Institutional framework for protection of children in India. Available from: www.unicef.org/india/institutional_and_legislative_framwork_ bajpai.pdf.

12. POCSO Act - Providing Child-Friendly Judicial Process. Press information Bureau, Governement of India, 2012. [Last cited on 2018 Aug 09] Available from:

http://pib.nic.in/newsite/efeatures.aspx.?relid=86150

13. Reporting child sexual abuse is mandatory under law, but the ill-equipped system often fails victims. (Last cited on 2018 July 22)

Available from: https://scroll.in/article/827189/reporting-childsexual-abuse-is-mandatory-under-law-but-the-ill-equippedsystem-often-fails-victims

14. Finkelhor D, Browne A. The traumatic impact of child sexual abuse: A conceptualization. Am J Orthopsychiatry. 1985;55(4):530-541. 
15. Kendall-Tackett K, Williams L, Finkelhor D. Impact of sexual abuse on children: A review and synthesis of recent empirical studies. Psychological Bull. 1993;113(1):164-180.

16. Browne A, Finkelhor D. Impact of child sexual abuse: A review of the research. Psychol Bull. 1986;99(1):66-77.

17. Arya Y, Chaturvedi A. Analysis of underreporting of cases of child sexual abuse in India. The World J Juristic Polity. ISSN: 2394- 5044. 2017

18. Breaking the Silence: Child Sexual Abuse in India, 2016. [Last cited on 2018 Aug 09]

https://www.hrw.org/sites/default/files/reports/india0113ForUp load.pdf

19. Brown H. Sexual abuse of children with disabilities. Protecting children from sexual violence. [Last cited on 2018 Aug 09] Available from :https://www.coe.int/t/dg3/children/1in5/Source/PublicationSe xualViolence/Brown.pdf
20. Subramaniyan V, Reddy P, Chandra G, Rao C, Rao T. Silence of male child sexual abuse in India: Qualitative analysis of barriers for seeking psychiatric help in a multidisciplinary unit in a general hospital. Indian J Psychiatry. 2017;59(2):202.

21. Empowerment and Rehabilitation of Children, Nov. 26, 2016. [Last cited on 2018 Aug 09] Available from https://www.unodc.org/pdf/india/publications/inventory_of_Sc hemes_and_Programmes/06_secti on4.pdf

22. Preserving Children's Rights: The Challenges of Eradicating Child Sexual Exploitation in Thailand and India, 22 Suffolk Transnat'l L. Rev. 259:1998-1999. 